\title{
The Psychoactive Designer Drug and Bath Salt Constituent MDPV Causes Widespread Disruption of Brain Functional Connectivity
}

\author{
Luis M Colon-Perez ${ }^{1,2}$, Kelvin Tran', Khalil Thompson', Michael C Pace ${ }^{3}$, Kenneth Blum', \\ Bruce A Goldberger ${ }^{1,4,5}$, Mark S Gold ${ }^{1,3}$, Adriaan W Bruijnzeel ${ }^{1,2,3}$, Barry Setlow ${ }^{1,2,3}$ and Marcelo Febo ${ }^{*, 1,2,3}$ \\ 'Department of Psychiatry, McKnight Brain Institute, University of Florida, Gainesville, FL, USA; ${ }^{2}$ Center for Addiction Research and Education, \\ University of Florida, Gainesville, FL, USA; ${ }^{3}$ Department of Neuroscience, McKnight Brain Institute, University of Florida, Gainesville, FL, USA; \\ ${ }^{4}$ Departments of Pathology, Immunology, and Laboratory Medicine, University of Florida, Gainesville, FL, USA; ${ }^{5}$ William R Maples Center for \\ Forensic Medicine, University of Florida, Gainesville, FL, USA
}

\begin{abstract}
The abuse of 'bath salts' has raised concerns because of their adverse effects, which include delirium, violent behavior, and suicide ideation in severe cases. The bath salt constituent 3,4-methylenedioxypyrovalerone (MDPV) has been closely linked to these and other adverse effects. The abnormal behavioral pattern produced by acute high-dose MDPV intake suggests possible disruptions of neural communication between brain regions. Therefore, we determined if MDPV exerts disruptive effects on brain functional connectivity, particularly in areas of the prefrontal cortex. Male rats were imaged following administration of a single dose of MDPV (0.3, I.0, or $3.0 \mathrm{mg} / \mathrm{kg}$ ) or saline. Resting state brain blood oxygenation level-dependent (BOLD) images were acquired at 4.7 T. To determine the role of dopamine transmission in MDPV-induced changes in functional connectivity, a group of rats received the dopamine $D_{1} / D_{2}$ receptor antagonist cis-flupenthixol $(0.5 \mathrm{mg} / \mathrm{kg}) 30 \mathrm{~min}$ before MDPV. MDPV dose-dependently reduced functional connectivity. Detailed analysis of its effects revealed that connectivity between frontal cortical and striatal areas was reduced. This included connectivity between the prelimbic prefrontal cortex and other areas of the frontal cortex and the insular cortex with hypothalamic, ventral, and dorsal striatal areas. Although the reduced connectivity appeared widespread, connectivity between these regions and somatosensory cortex was not as severely affected. Dopamine receptor blockade did not prevent the MDPV-induced decrease in functional connectivity. The results provide a novel signature of MDPV's in vivo mechanism of action. Reduced brain functional connectivity has been reported in patients suffering from psychosis and has been linked to cognitive dysfunction, audiovisual hallucinations, and negative affective states akin to those reported for MDPV-induced intoxication. The present results suggest that disruption of functional connectivity networks involving frontal cortical and striatal regions could contribute to the adverse effects of MDPV.

Neuropsychopharmacology (20 I6) 4I, 2352-2365; doi:I0.I038/npp.20I6.40; published online I3 April 20I6
\end{abstract}

\section{INTRODUCTION}

There has been a growing number of serious cases of bath salt intoxication in the United States, with nearly 23000 emergency room visits registered in 2013 (Substance Abuse and Mental Health Services Administration (SAMHSA, 2014)). Designer cathinones present in bath salts are widely abused and have adverse effects on mental health. Some users are under the false impression that bath salts are safe, legal, and non-addictive alternatives to illicit psychostimulants, such as cocaine, methamphetamine (METH), and methylenedioxy-methamphetamine (MDMA). Bath salts can contain one or a mixture of cathinone derivatives, many of

*Correspondence: Dr M Febo, Department of Psychiatry, University of Florida Brain Institute, PO Box 100256, Gainesville, FL 326I0, USA, Tel: + I 352294 49|।, Fax: + I 352392 8217, E-mail: febo@ufl.edu Received 18 December 2015; revised II March 2016; accepted 16 March 2016; accepted article preview online 21 March 2016 which act as powerful stimulants. A growing number of reports highlight the negative mental health consequences of bath salts (Marder, 2012). This is particularly the case with the bath salt constituent 3,4-methylenedioxy-pyrovalerone (MDPV), which has been involved in numerous cases of bath salt intoxication in the US Clinical reports, indicating that MDPV users treated for acute intoxication show behavioral disturbances produced by acute intake that can last beyond 4 weeks (Prosser and Nelson, 2012; Shulgin, 2009). Acute intoxication produces typical stimulant-like effects, including increased energy, euphoria, and elevated feelings of empathy, and sociability. The 'crash' that follows involves negative affective states, such as depression, suicidal thoughts, anxiety, panic attacks, excited delirium, bouts of violent aggression towards self and others, and combativeness (Haiken, 2012; Penders and Gestring, 2011; Stevenson and Tuddenham, 2014; Stoica and Felthous, 2013; Thornton et al, 2012), that resemble a severe psychotic episode (John et al, 2014). The neurobiological mechanisms that contribute to the initial 
positive effects are an active area of preclinical research (Bonano et al, 2014; Watterson et al, 2012); however, factors contributing to the postreward crash are unclear. Despite growing evidence that MDPV's rewarding effects are mediated through the dopamine transporter (DAT) (Kolanos et al, 2013), its other reported psychotropic effects (Murray et al, 2012; Penders and Gestring, 2011; Seely et al, 2013; Stevenson and Tuddenham, 2014) suggest additional central actions. In particular, it seems likely that the mechanisms of the acute reinforcing effects of MDPV intake differ from the later-onset effects (Prosser and Nelson, 2012; Shulgin, 2009). Acute effects of MDPV at low-to-moderate doses are likely to involve brain reward regions targeted by other stimulants, such as cocaine and METH (Baumann et al, 2012; Simmler et al, 2013), whereas higher doses have the potential to influence other brain networks (Penders and Gestring, 2011). Given the nature of the reported behavioral disturbances, it is possible that MDPV causes disruptions in the coherent interactions among brain regions that are necessary for normal cognition and affect, as reported in other neuropsychiatric conditions involving audiovisual hallucinations (Anticevic et al, 2013; Lui et al, 2009; Sommer et al, 2012; Wolf et al, 2011).

Animal imaging provides a novel and noninvasive approach to assess the effects of MDPV in the intact brain. Traditional functional magnetic resonance imaging (fMRI) and functional connectivity analysis have been used to investigate the neural actions of stimulants in rodents (Febo et al, 2005; Kaufman et al, 1998; Li et al, 2000; Luo et al, 2004; Marota et al, 2000; Zuo et al, 2011). Functional MRI studies in rats indicated that cocaine increases neural activity in the prefrontal cortex, and in the nucleus accumbens (NAc) and dorsal striatum (Febo et al, 2004a, b; Lu et al, 2012a). Cocaine also reduces functional connectivity in mesolimbic and mesocortical brain areas (Lu et al, 2014), as well as in other non-reward-related brain regions (Li et al, 2000). Therefore, we predicted that MDPV administration would elicit similar reductions in functional connectivity between the NAc and the prefrontal cortex. The core of the NAc and the prelimbic area of the prefrontal cortex show resting and evoked coherent activity (Ewing and Grace, 2013; McCracken and Grace, 2009). Prefrontal synaptic inputs drive plasticity in the core of the NAc (Kombian and Malenka, 1994), and cocaine and other drugs of abuse impair plasticity in these regions of the reward system (Shen and Kalivas, 2013). Loss of coherent brain activity in these brain reward regions could potentially underlie the adverse behavioral effects of MDPV. We observed that MDPV caused a significant, widespread, and dose-dependent disruption of functional connectivity, which involved frontal cortical, striatal, and hypothalamic brain regions, and also areas outside of the mesocorticolimbic system. Impaired connectivity involving these structures could represent one mechanism by which this drug causes negative cognitive and emotional effects.

\section{MATERIALS AND METHODS}

\section{Subjects}

Adult male Long Evans rats $(n=45 ; 250-300 \mathrm{~g}$ at the start of the experiments) were obtained from Charles River Laboratories (Wilmington, MA, USA) and housed in pairs in a temperature- and humidity-controlled vivarium (12 h lightdark cycle with lights off at 1900 hours). Food and water were available ad libitum. Experiments and procedures received prior approval by the Institutional Animal Care and Use Committee of the University of Florida and followed all applicable NIH guidelines.

\section{Drug Treatments and Preparations for Functional Imaging}

MDPV hydrochloride and cis-flupenthixol dihydrochloride were purchased from Sigma-Aldrich Chemical Co. (St Louis, MO). These were dissolved in $0.9 \%$ sterile saline and administered intraperitoneally before induction of anesthesia. For the dose-response functional imaging study, MDPV $(0.3,1.0$, or $3.0 \mathrm{mg} / \mathrm{kg})$ or saline was administered $50-60 \mathrm{~min}$ before acquiring the resting state fMRI data sets (Figure 1). This time point was chosen because there is potentiation of brain reward function by MDPV doses in the range of $0.32-$ $3.2 \mathrm{mg} / \mathrm{kg}$ (subcutaneously) within the first $100 \mathrm{~min}$ after administration (Bonano et al, 2014), whereas the hyperthermia and putative effects on cerebral blood flow have subsided by $40 \mathrm{~min}$ (Wakabayashi et al, 2015). Plasma concentrations of major MDPV metabolites are still low at this time, whereas MDPV is highly concentrated in dorsal striatal tissue and is still present at almost 50\% peak plasma concentrations (Anizan et al, 2014; Novellas et al, 2015). Rats were administered sterile saline $(1 \mathrm{ml} / \mathrm{kg}$, intraperitoneally) or a single dose of MDPV (in mg/kg: 0.3, 1.0, and 3.0; $n=7-8$ rats per dose) 25 min before induction of anesthesia using 3-4\% isoflurane delivered in medical grade air (70\% nitrogen/30\% oxygen; air flow rate $1.5 \mathrm{ml} / \mathrm{min}$ ). Once induced, isoflurane was lowered to $2 \%$ for setup procedures and rats were given a single subcutaneous injection of the sedative agent dexmedetomidine $(0.02 \mathrm{mg} / \mathrm{kg})$. The additional sedative treatment allowed the entire 24-min imaging session to be performed while rats were under $0.5 \%$ isoflurane (Grandjean et al, 2014). Set up time took $20-30 \mathrm{~min}$, and thus rats were imaged at 50-60 min following the saline or MDPV injection (Figure 1a).

For the dopamine receptor blockade imaging study, the non-selective dopamine $\mathrm{D}_{1} / \mathrm{D}_{2}$ receptor antagonist cis-flupenthixol was administered at a dose of $0.5 \mathrm{mg} / \mathrm{kg}$ (intraperitoneally) $30 \mathrm{~min}$ before $3.0 \mathrm{mg} / \mathrm{kg} \mathrm{MDPV}$ (Figure 1b). Administration of this dose of the dopamine antagonist has been reported to reduce the conditioned reinforcing effects of cocaine (Wenzel et al, 2013) and cocaine taking and seeking, without affecting similar parameters for sucrose intake (Veeneman et al, 2012). In addition, this dose does not produce catatonia or other extrapyramidal motor effects in rats (Veeneman et al, 2012; Wenzel et al, 2013). Rats in this group were imaged $60 \mathrm{~min}$ after MDPV (90 min after cisflupenthixol). Data from the flupenthixol+3.0 mg/kg MDPV group were compared with the MDPV-alone group.

To sum, a total of 37 rats were used for the imaging, which included saline controls $(n=7), \mathrm{MDPV}$ at $0.3 \mathrm{mg} / \mathrm{kg}$ $(n=7), 1.0 \mathrm{mg} / \mathrm{kg} \quad(n=8)$, and $3.0 \mathrm{mg} / \mathrm{kg} \quad(n=8)$, and flupenthixol+3.0 mg/kg MDPV $(n=7)$. One week after imaging, the same dose of the corresponding drug or saline treatment was administered to a subset of these 37 rats and locomotor activity was measured (experiment details and group sizes provided below). 


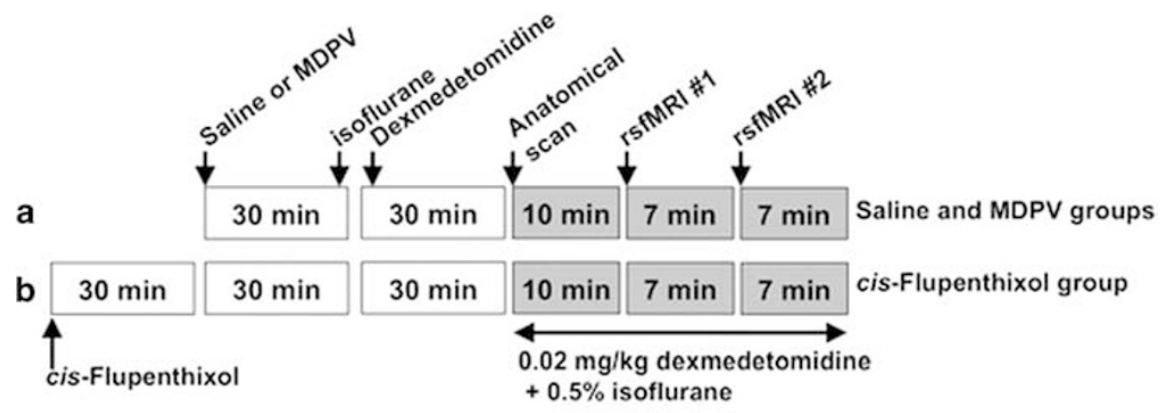

Locomotor activity study design

c $60 \mathrm{~min} 90 \mathrm{~min}$

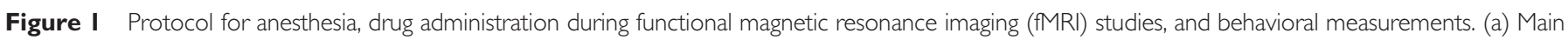

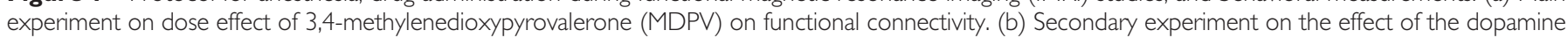

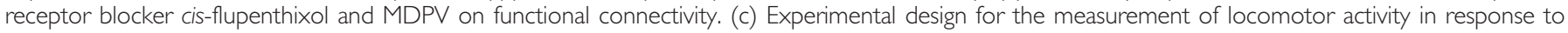
MDPV (intraperitoneal doses: 0, 0.3, and $3.0 \mathrm{mg} / \mathrm{kg}$ ) and $0.5 \mathrm{mg} / \mathrm{kg}$ intraperitoneal cis-flupenthixol $30 \mathrm{~min}$ before $3.0 \mathrm{mg} / \mathrm{kg}$ MDPV.

\section{Functional Magnetic Resonance Imaging}

Rats were imaged under low doses of anesthetic dexmedetomidine $(0.02 \mathrm{mg} / \mathrm{kg})$ and isoflurane $(0.5 \%)$. Pilot studies indicated that this combination of anesthetics, which is similar to that reported previously (Lu et al, 2012b), allows the measurement of stable, resting state fMRI activity across subjects. This anesthetic regimen was designed with the aim of rapid throughput for short imaging sessions, as rats are awake within minutes after returning to their home cages. Core body temperature and spontaneous respiratory rates were continuously recorded during MRI scanning (SA Instruments, Stony Brook, NY). Rats were maintained at normal body temperature levels $\left(37-38^{\circ} \mathrm{C}\right)$ using a warm water recirculation system.

Images were collected on a $4.7 \mathrm{~T} / 33 \mathrm{~cm}$ horizontal magnet (Magnex Scientific) with an $11.5 \mathrm{~cm}$ diameter gradient insert (Resonance Research, Billerica, MA) (670 mT/m maximum gradient strength at 300Amps and $120 \mu$ s rise time) and controlled by the VnmrJ 3.1 software (Agilent, Palo Alto, $\mathrm{CA})$. A quadrature transmit/receive radiofrequency (RF) coil tuned to $200.6 \mathrm{MHz}{ }^{1} \mathrm{H}$ resonance was used for $\mathrm{B}_{1}$ field excitation and RF signal detection (airmri; LLC, Holden, MA). Functional images were collected using a 2-shot spinecho echo-planar imaging (EPI) sequence (echo time $=50 \mathrm{~ms}$ and repetition time $=1 \mathrm{~s}$ ) with the following geometric parameters: $32.5 \times 32.5 \mathrm{~mm}^{2}$ in plane, 12 slices at $1.5 \mathrm{~mm}$ thickness per slice, data matrix $=64 \times 64(508 \mu \mathrm{m}$ in-plane resolution). Spin echo sequences for functional MRI studies have been well characterized in the literature (Diekhoff $\mathrm{et} \mathrm{al}$, 2011; Duong et al, 2002, 2003; Febo et al, 2004b; Goense and Logothetis, 2006; Harmer et al, 2012; Poser and Norris, 2007; Sanchez Panchuelo et al, 2015; Yacoub et al, 2003). It should be noted that for resting state fMRI, it was recently shown that spin-echo EPI provide adequate resting state functional localization that improves upon gradient echo sequences, especially when confounds related to signal dropouts need to be minimized (Chiacchiaretta and Ferretti, 2015). A total of 200 repetitions per EPI scan were collected (6 min and $40 \mathrm{~s}$ ), with two EPI scans collected per rat. No stimuli were presented during functional scanning. Anatomical scans for image overlay and reference-to-atlas registration were collected using a fast spin echo sequence $(\mathrm{TE}=45 \mathrm{~ms}$; $\mathrm{TR}=2 \mathrm{~s}$; RARE factor $=8$; number of averages $=10$ ) with the same dimensions as the EPI scan, but at a higher resolution $(256 \times 256$ in plane for a resolution of $127 \mu \mathrm{m})$.

\section{Image Processing and Analysis}

Brain masks were manually created on itkSNAP (www. itksnap.org) using high-resolution anatomical scans to remove non-brain voxels. Cropped images were registered to an atlas of the rat brain using the FMRIB Software Library linear registration program flirt (Jenkinson et al, 2002). The atlas is segmented into 174 brain regions spanning olfactory bulb to the lower brainstem of the rat (Ekamsolutions LLC, Holden, MA) (Figure 2). Registration matrices were saved and used to subsequently transform functional data sets into atlas space for preprocessing and analysis. Functional images were realigned to the first image in the time series. Slice timing correction was applied and time-series spikes were removed using Analysis of Functional NeuroImages (AFNIs) (Cox, 1996). Linear and quadratic detrending and spatial blurring was applied to all images, and these were intensity normalized. Six head motion parameters, and cerebroventricular and white matter signals were removed from all data sets. A voxelwise temporal bandpass filter (between 0.01 and $0.1 \mathrm{~Hz}$ ) was applied to remove brain signals that contain cardiac and respiratory frequencies. Spontaneous BOLD signals were extracted from a total 150 regions of interest (ROIs) (75 ROIs in the left and 75 in the right hemisphere) based on the atlas-guided seed location. Signals were averaged from voxels within ROI located in each hemisphere. 
a

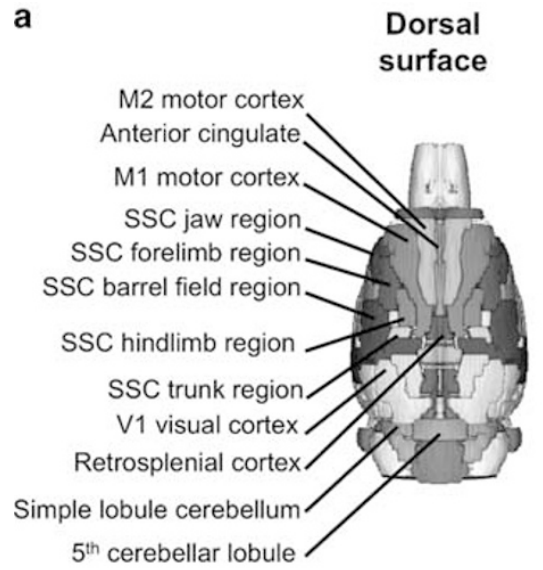

Ventral

surface

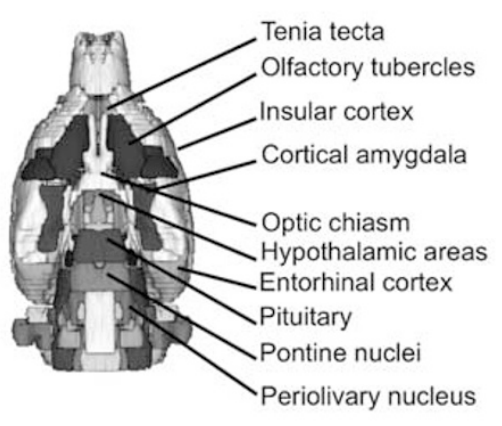

b

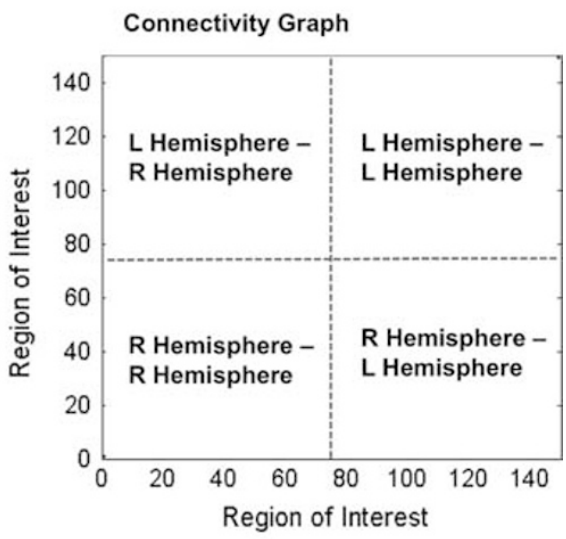

C Regions of Interest
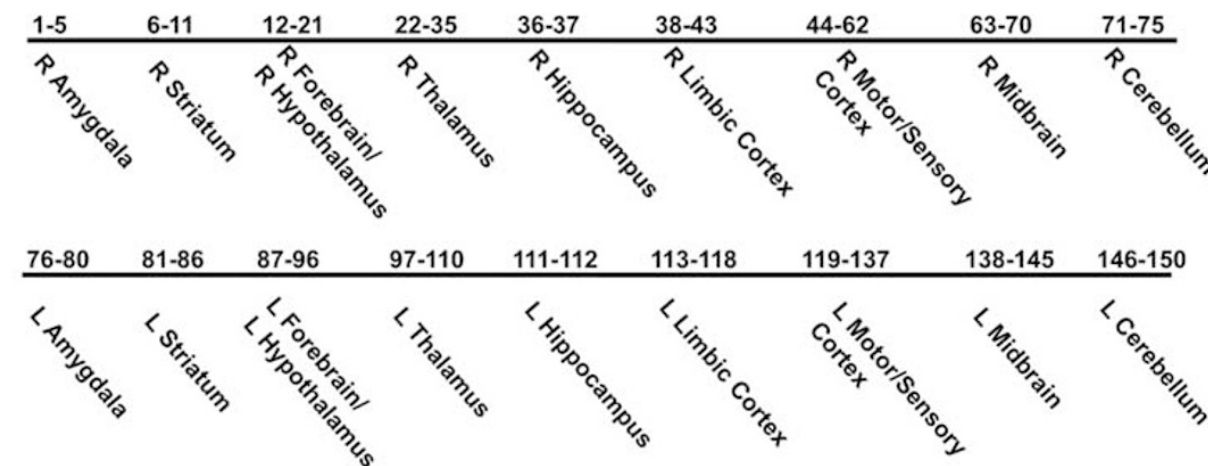

Figure 2 Functional image parcellation based on a segmented atlas of rat brain. (a) Rat brain atlas in 3D view highlighting the dorsal and ventral surface brain areas. (b) Pairwise correlations of resting state signals from 150 regions of interest were assessed. Both intra- and inter-hemispheric comparison correlations are included in subsequent graphs, as indicated in the graph. (c) Regions analyzed for functional connectivity shown in the order in connectivity graph in (b). L, left; R, right; SSC, somatosensoricortical.

Cross-correlations between the extracted fMRI signals per each ROI were carried out to create correlation coefficient (Pearson's r) maps. The first nine images in each functional time series were not used in the cross-correlation step. Pearson's $r$ maps were then subjected to a voxelwise z-transformation. Two correlation maps were averaged per subject to generate a single correlation map subsequently used for statistical comparisons. AFNI's 3dttest++ was used to compare MDPV doses to saline to map changes in functional connectivity with drug treatment. For the resultant composite statistical maps, AFNI's 3dClustSim program was used to determine the adequate cluster size for a given uncorrected $p$-value. The resultant voxel cluster size at $p<0.05$ was used to control the level of false-positive rates in the final group statistical maps. Our preliminary assessment of data sets shows a consistent and symmetrical pattern of brain resting state network organization using this approach (Supplementary Figure 1). To further assess brain network level changes in functional connectivity, $z$-score values for the 150 ROIs were imported into Matlab (Natick, MA) and two-tailed unpaired $t$-tests (with heteroscedastic variances) were used to compare MDPV to saline groups. Because the large-scale data sets involving $0.5 n(n-1)$ pairwise comparisons for 150 nodes per each subject could lead to increased type I errors, a false discovery rate (FDR) algorithm was implemented in Matlab (Storey, 2002).
Symmetrical graphs of group z-scores and FDR corrected $p$-values were constructed to compare saline and MDPV groups (Figures 4 and 6). Statistical tests comparing functional connectivity per individual ROI's are indicated in figure legends. In most cases, a one-way analysis of variance (ANOVA with Sidak's multiple-comparison post hoc test; drug treatment as an independent variable) or a $t$-test between means of saline and MDPV groups was used. Statistical comparisons were carried out using Matlab software or GraphPad Prism 6.0.

\section{Temperature and Respiratory Measurements}

As part of the general neuroimaging procedures, rectal temperature was measured using a thermocouple probe and respiratory strokes were measured noninvasively using a force transducer (SA Instruments, Stony Brook, NY). One-way ANOVA with drug treatment as the independent variable was used to compare groups on these measures (significant $p<0.05$ ).

\section{Locomotor Activity Measurements}

Locomotor and stereotypic activity in response to MDPV was measured using an automated activity monitoring system (Accuscan Instruments, Columbus, OH). Details of 
the test arenas and control software are provided in previous publications (Febo et al, 2003, 2002). Animals were tested 1 week after imaging. The four groups consisted of rats given saline $(n=7), \mathrm{MDPV}(0.3 \mathrm{mg} / \mathrm{kg}, n=7 ; 3.0 \mathrm{mg} / \mathrm{kg}, n=6)$, or cis-flupenthixol+3.0 mg/kg MDPV $(n=8)$. Rats were placed into test arenas to habituate for $60 \mathrm{~min}$ (Figure 1c). They then received an intraperitoneal injection of saline or cis-flupenthixol $(0.5 \mathrm{mg} / \mathrm{kg}$, intraperitoneally). After $30 \mathrm{~min}$, they received another intraperitonealinjection of saline or MDPV. Locomotor activity was measured during the entire test session, which included the $60 \mathrm{~min}$ habituation period, the pretreatment period, and a $90-\mathrm{min}$ period after MDPV or saline. Behavioral results were analyzed using a two-way ANOVA with drug groups $\times$ time as independent variables (time as a repeated factor; significant $p<0.05$ ).

\section{Blood Pressure and Arterial Oxygen Measurements}

In a separate group of eight rats, heart rate and percent realtime arterial oxygen saturation (in \% of functional arterial hemoglobin; $\mathrm{SpO}_{2}$ ) were noninvasively measured (MouseOx system from STARR Life Sciences Corp, Oakmont, PA, coupled with a rat foot sensor). In a group of four rats, these studies were carried out to determine whether animals under the dexmedetomidine and isoflurane sedation used for the imaging studies showed stability in these systemic physiological variables. In another group of four rats, these studies were conducted under the same conditions but rats were administered $3 \mathrm{mg} / \mathrm{kg} \mathrm{MDPV}$. In both experiments, the sequence of treatments for dexmedetomidine, isoflurane and MDPV were as described in the above sections (Figure 1). The foot sensor was placed in between the metarsal pads and just above the tarsal pads. The recordings were performed at a rate of $5 \mathrm{~Hz}$ and were monitored for $20 \mathrm{~min}$.

\section{RESULTS}

\section{Detection of Rat Brain Network Functional Connectivity Using Seed-Based Analysis}

Seed-based functional connectivity analysis is often used to identify spontaneous coherent networks in rat brain (Pawela et $a l, 2008)$. In the present study, a cross-correlation procedure resulted in the identification of networks associated with spontaneous BOLD activation measured using seed ROIs based on a segmented atlas of rat brain (Ferris et al, 2015). Based on the known functional neuroanatomy affected by psychostimulants, the chosen ROIs included subregions of the prefrontal cortex, ventral and dorsal striatum, sensory, motor, association cortices, midbrain, and memory networks. The connectivity patterns with several of these brain regions are illustrated in composite maps in Supplementary Figure 1. Significant coherent BOLD activity occurred with structures near the vicinity (within several slices) of seed regions. However, in general, these followed a connectivity pattern that is consistent with published studies (Jonckers et al, 2014; Lu et al, 2012b, 2014; Pawela et al, 2008). Importantly, comparisons of in vivo functional connectivity patterns to functional connectivity patterns in fresh and fixed post-mortem brain tissue indicate that the patterns are not the result of technical artifacts arising from image acquisition (radiofrequency, gradient noise, etc.) or artifacts from the analysis and processing procedure (Supplementary Figure 2).

\section{Dose-Dependent Effect of MDPV on Functional Connectivity}

Group statistical comparisons of saline control and MDPV dose groups (for NAc and prelimbic area seeds) are shown in Figure 3 (group statistical t maps show voxel activations at a threshold of $t=3.7 p \leqslant 0.05$, cluster-size corrected, $n=7-8$ ). Functional connectivity with NAc or prelimbic area seed is shown in the left column (Figures $3 \mathrm{a}$ and b). Qualitative comparisons are made to the whisker barrel field somatosensoricortical (SSC) area (Figure 3c). A single seed for one hemisphere is shown for each of these brain regions (Figure 3, green arrows). Administration of $0.3 \mathrm{mg} / \mathrm{kg}$ MDPV did not significantly alter connectivity with NAc or prelimbic area, whereas significant decreases in connectivity were observed with the higher doses of MDPV (1.0 and $3.0 \mathrm{mg} / \mathrm{kg}$ ). The most potent effect on functional connectivity was observed with the highest dose, which caused a robust reduction in functional connectivity with the NAc and prelimbic area. Interestingly, as shown in Figures $3 a$ and $b$, caudal regions far from seed regions showed modest but significant increases in functional connectivity. This effect was noticeably significant in the midbrain near the ventral tegmental area (VTA)/substantia nigra and periaqueductal gray (in the case of the NAc seed; Figure 3a) and in the insular cortex and hypothalamus (in the case of the prelimbic seed region; Figure $3 \mathrm{~b}$ ). It should be noted that in the case of the SSC barrel field seed, there was not a significant effect of the $1 \mathrm{mg} / \mathrm{kg}$ dose, and the reduction in functional connectivity caused by the higher dose was noted in the contralateral region and the sensory thalamus (Figure $3 \mathrm{c}$ ). Contrary to the NAc and prelimbic seeds, we did not observe increased connectivity in any areas when the barrel field was chosen as the seed region (Figure 3c).

We next analyzed functional connectivity across 150 anatomically defined ROIs. The functional connectivity analysis was represented as adjacency matrices (Albert and Barabasi, 2002). The matrices were constructed using the correlation coefficient values (Fisher's $\mathrm{z}$ transformed) for each pair of ROIs. This yielded graphs reflecting functional connectivity patterns in saline control and MDPV-treated rats. Figure 4 shows the composite graphs for the rats in these groups $(n=7)$. The layout of the composite graphs, which show the intra- and interhemispheric correlations of the functional and anatomical groups, is displayed in Figure $2 \mathrm{~b}$. The graph emphasizes the location of segregated groups of ROIs. Figure 2c summarizes the list of 150 ROIs in the same order in which they are presented on the graphs. The ROIs include learning and memory regions, cortico striatal areas, sensorimotor, and amygdala areas. In the saline-control rats, there is a visibly robust segregation of high-correlated BOLD activity around groups of functionally and anatomically related brain regions. The graphical representations were stable and robust for the networks, as emphasized by the strikingly similar spatial pattern of global connectivity that was observed between the saline group and the group given the lowest dose of MDPV $(0.3 \mathrm{mg} / \mathrm{kg}, n=7)$ (Figure 4, top two left panels). In these two groups, there was 
a

Seed: NAc Core

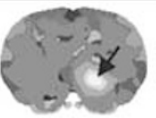

$1.0 \mathrm{mg} \mathrm{kg}^{-1}$ vs saline
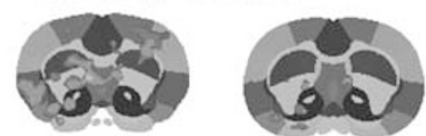

$3.0 \mathrm{mg} \mathrm{kg}^{-1}$ vs saline

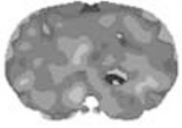

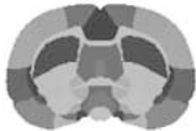
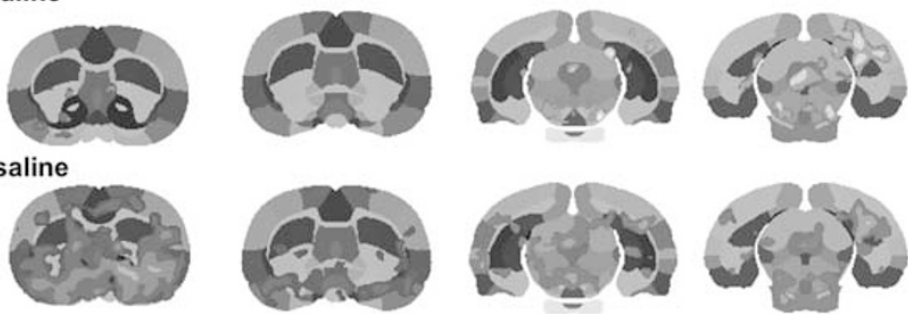

b

Seed: Prelimbic area

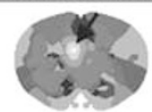

$1.0 \mathrm{mg} \mathrm{kg}^{-1}$ vs saline
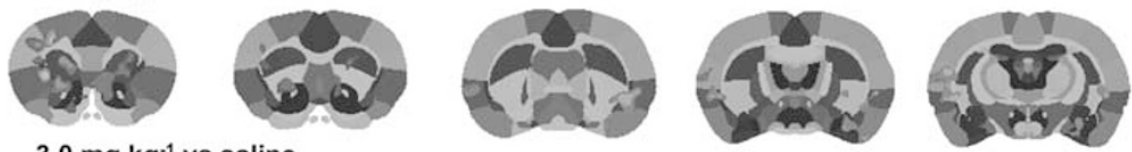

$3.0 \mathrm{mg} \mathrm{kg}^{-1}$ vs saline
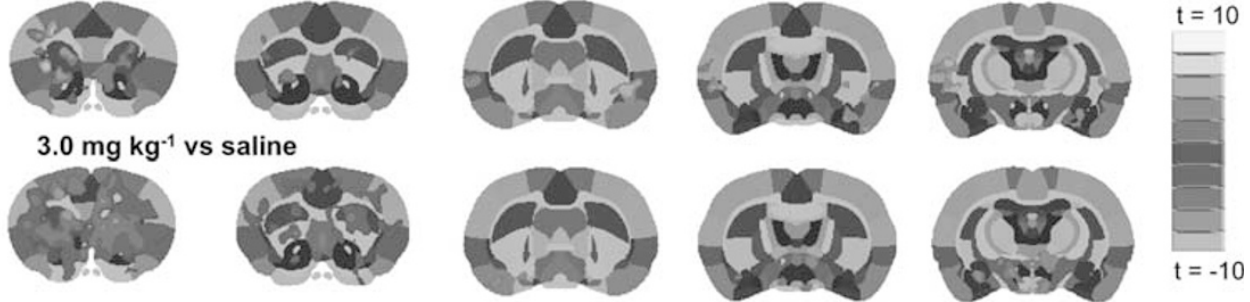

Seed: SSC Barrel field
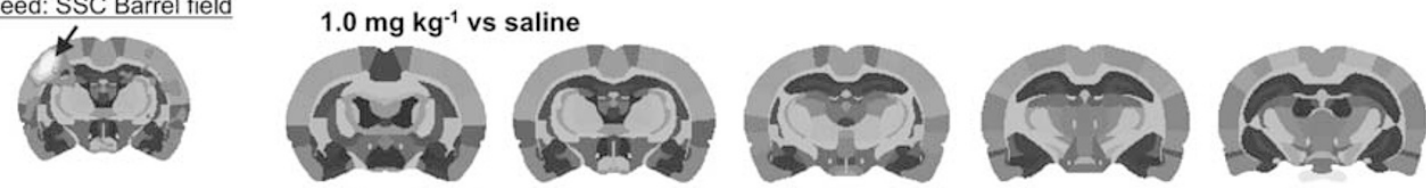

$3.0 \mathrm{mg} \mathrm{kg}^{-1}$ vs saline
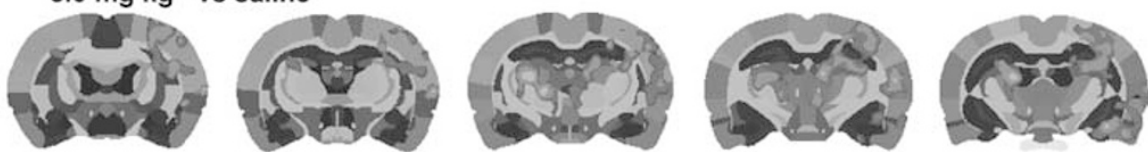

Figure 3 3,4-methylenedioxypyrovalerone (MDPV) dose-dependently reduces functional connectivity with the nucleus accumbens (NAc) (a), prelimbic cortex (b) and somatosensory cortex (SSC) (c). Composite statistical map for each seed region is shown in the upper left corner in (a-c) $(n=7 ; t=3.7$ $p<0.05$, cluster-size corrected). Green arrow shows seed region. Rows of statistical maps on the right group level differences in functional connectivity between saline and I-3 mg/kg MDPV. Statistical comparison maps are illustrated for (a) NAc core, (b) prelimbic area, and (c) SSC - barrel field region (t-test $t \geq 3.7, p \leqslant 0.05$, cluster-size corrected). Scale bar represent $t$ values (warm colors = positive $t$-values and cool colors $=$ negative $t$-values). A full color version of this figure is available at the Neuropsychopharmacology journal online.
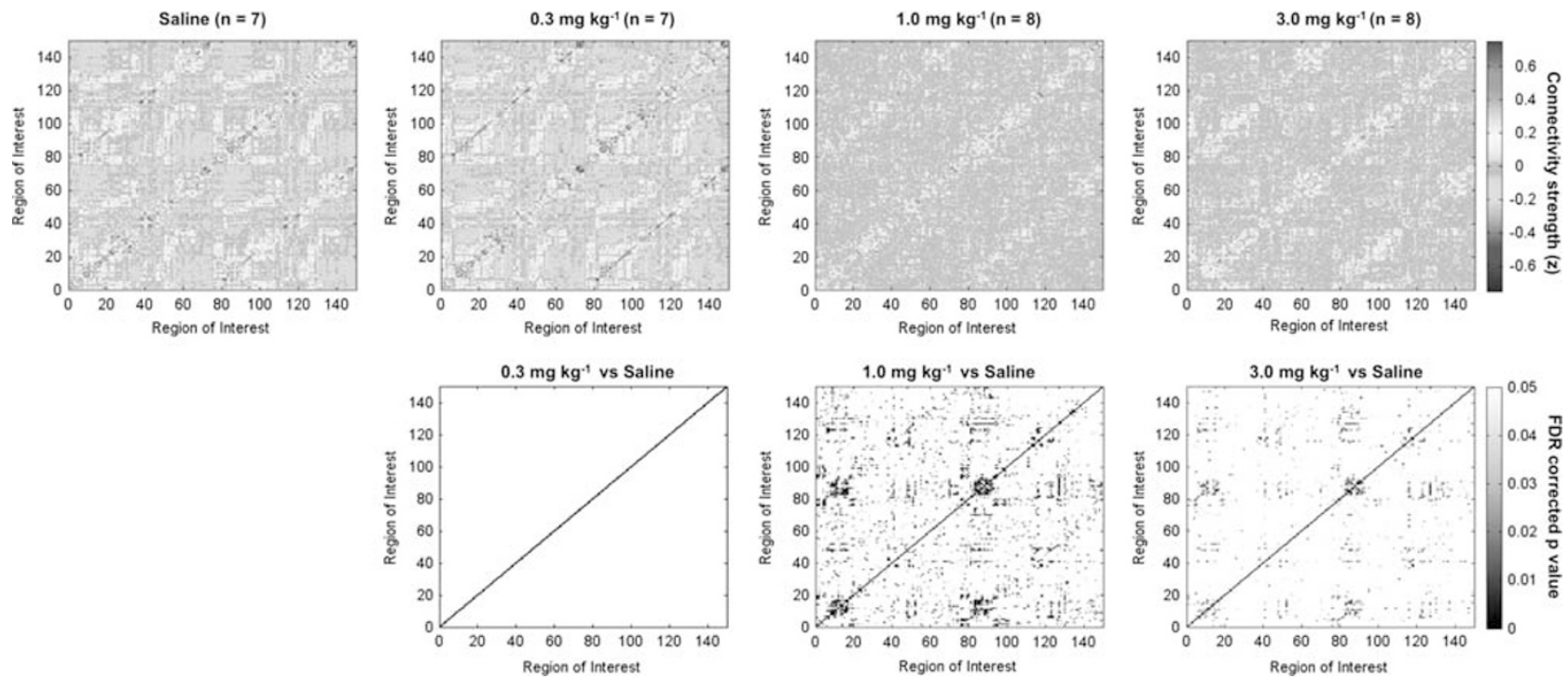

Figure 4 Highest doses of 3,4-methylenedioxypyrovalerone (MDPV) cause widespread reductions of functional connectivity. Top row shows composite connectivity graphs for saline and three doses of MDPV (in mg/kg: 0.3, I.0, and 3.0). Matrix entries are Fisher's z-transformed correlation coefficients. Color inside the graph indicates the value of the $z$, with red-yellow indicating high positive correlations, yellow-to-light blue low correlations, and dark blue anticorrelated signals. Bottom row shows graphs for statistical comparisons between saline and each of the MDPV treatment conditions. Gray-scale intensity indicates the level of statistical significance, with lightest colors approaching a cutoff of $p=0.05$ (false discovery rate (FDR) corrected). A full color version of this figure is available at the Neuropsychopharmacology journal online. 
a similar pattern of segregated organization around anatomical and functional regions (Figure 4). Statistical comparisons confirmed that in all of the 150 ROIs tested there, were no differences (Figure 4; FDR corrected $t$-test comparing saline vs $0.3 \mathrm{mg} / \mathrm{kg}$ MDPV means). However, when compared with the saline group, both the middle and high doses of MDPV (1.0 and $3.0 \mathrm{mg} / \mathrm{kg}$, respectively) caused powerful reductions in functional connectivity $(p<0.05$ FDR corrected; Figure 4). This effect was significant and consistent across data from individual subjects. We confirmed this by examining the variance distribution across connectivity graphs for all treatment groups (Supplementary Figure 3). These showed a modest degree in variance (SDs $<0.3$ ), with the group showing the highest degree of variability corresponding to the $0.3 \mathrm{mg} / \mathrm{kg}$ MDPV group (Supplementary Figure 3).

It is important to note that the reduction in functional connectivity with the two highest doses of MDPV did show anatomical specificity. The segregated patterns in the connectivity graphs (Figure 4, bottom right) illustrate the regional specificity of MDPV. The specificity of the effects of MDPV is further supported by measurement of functional connectivity between specific brain reward regions in the saline and $3.0 \mathrm{mg} / \mathrm{kg}$ conditions (Figure 5). MDPV caused a significant reduction in functional connectivity between the NAc core and various striatal, forebrain, and frontal cortical areas ( $t$-test, $p=0.05$; Figure 5a). The effect of MDPV on NAc core connectivity appeared widespread across brain areas. Yet, this was not the case for the prelimbic region. This region showed a reduced connectivity only with other frontal cortical areas within its vicinity, including the infralimbic and orbital cortices (Figure 5b). The more laterally located insular cortex (Figure 5c), however, showed a significant reduction in functional connectivity, with similar areas showing connectivity with the NAc core. Finally, no effect of MDPV on functional connectivity was observed in response to MDPV in the SSC barrel field cortex. A primary reason behind this lack of effect is the low level of functional connectivity between this region and striatal, forebrain, and frontal cortical areas in the saline group (Figure 5d).

\section{Effect of Dopamine Receptor Blockade on Globally Disrupted Connectivity Produced by High-Dose MDPV}

MDPV is known to be a powerful DAT blocker (Bonano et al, 2014; De Felice et al, 2014; Kolanos et al, 2013), and it prolongs elevations in extracellular dopamine in the striatum to a greater extent than cocaine (Baumann et al, 2012). It is possible that this robust elevation in dopamine levels affects many regions of the brain and may constitute one mechanism by which MDPV reduces brain functional connectivity. To test this hypothesis, we administered the nonselective dopamine $\mathrm{D}_{1} / \mathrm{D}_{2}$ receptor antagonist cis-flupenthixol at a dose of $0.5 \mathrm{mg} / \mathrm{kg} 30 \mathrm{~min}$ before $3.0 \mathrm{mg} / \mathrm{kg}$ MDPV treatment to test whether it prevents the globally reduced functional connectivity. To maintain consistency across treatment conditions, rats were provided the same temporal sequence of anesthetics as the saline or MPDV-alone groups (Figure 1). As shown in Figure 6, cis-flupenthixol did not affect the MDPV-induced reduction in functional connectivity.
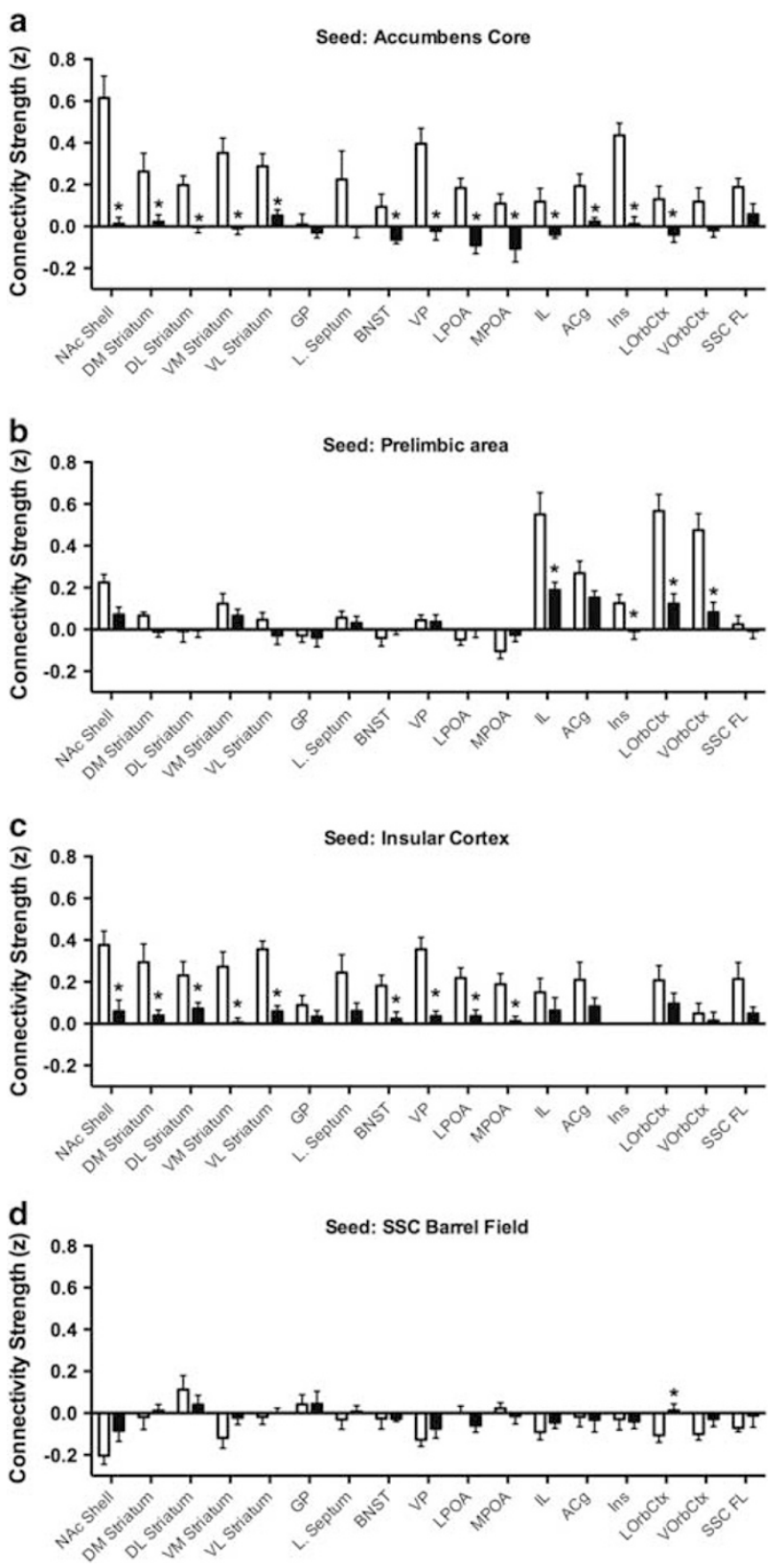

Figure 5 Nucleus accumbens, insular, and prelimbic cortex, but not barrel field cortex, are affected by high dose 3,4-methylenedioxypyrovalerone (MDPV). Open bars show data for saline group and closed bars MDPV $(3 \mathrm{mg} / \mathrm{kg})$. Assessments are made between each seed region and striatal, forebrain, hypothalamic, and cortical areas. (a) Nucleus accumbens core is seed. (b) Prelimbic area is seed. (c) Insular cortex is seed. (d) Barrel field cortex is seed. *Significant differences at $p<0.05$ using a $t$-test. Data are shown as mean \pm SE. ACg, anterior cingulate cortex; BNST, bed nucleus of stria terminalis; $D / M / L N$, dorsal/medial/lateral/ventral; IL, infralimbic; Ins, insular cortex; LOrbCtx, lateral orbital cortex; LPOA, lateral preoptic area; MPOA, medial preoptic area; NAc, nucleus accumbens; SSC FL, somatosensory cortex-forelimb area; VOrbCtx, ventral orbital cortex; VP, ventral pallidum.

\section{Behavioral Results}

To determine whether the dose of cis-flupenthixol was effective in modulating the behavioral response to high-dose MDPV, locomotor activity and stereotypy were evaluated following administration of saline vehicle, 0.3 or $3.0 \mathrm{mg} / \mathrm{kg}$ 

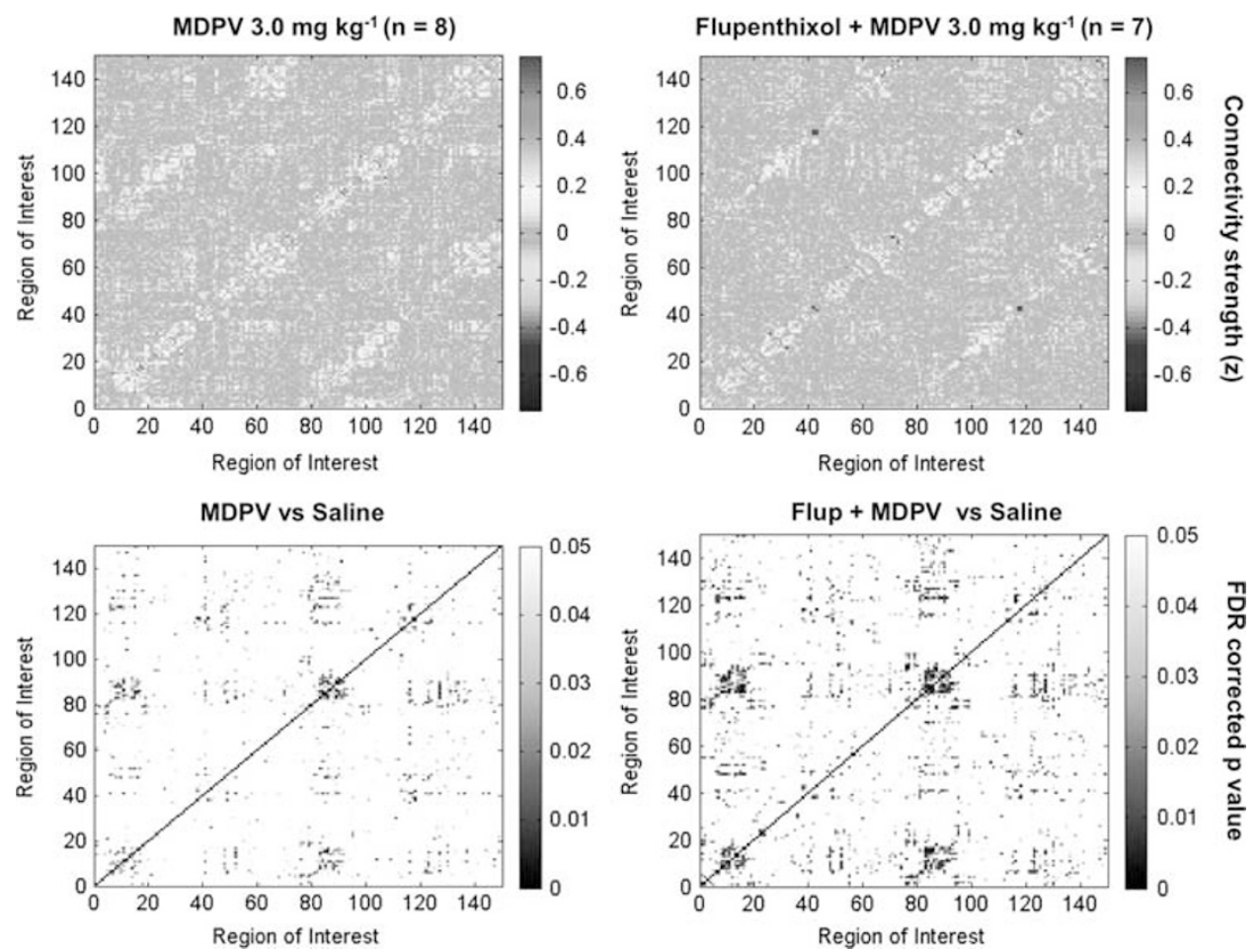

Figure 6 Pretreatment with the $D_{1} / D_{2}$ receptor blocker cis-flupenthixol (Flup) does not prevent the effect of 3,4-methylenedioxypyrovalerone (MDPV) on functional connectivity. Top left, $3.0 \mathrm{mg} / \mathrm{kg}$ MDPV without Flup $(n=8)$. Top right, pretreatment with $0.5 \mathrm{mg} / \mathrm{kg}$ cis-flupenthixol before $3.0 \mathrm{mg} / \mathrm{kg} \mathrm{MDPV}$ ( $n=7$ ). Matrix entries are Fisher's z-transformed correlation coefficients. Color inside the graph indicates the value of the z, with red-yellow indicating high positive correlations, yellow-to-light blue low correlations, and dark blue anticorrelated signals. Bottom row shows graphs for statistical comparisons between saline and each of the MDPV treatment conditions (without and with flupenthixol). Gray-scale intensity indicates the level of statistical significance, with lightest colors approaching a cutoff of $p=0.05$ (false discovery rate (FDR) corrected). A full color version of this figure is available at the Neuropsychopharmacology joumal online.

MDPV, or $3.0 \mathrm{mg} / \mathrm{kg}$ MDPV+cis-flupenthixol (Figures $7 \mathrm{a}$ and b). For both stereotypy and locomotor activity, there were no significantly different time points between saline and the $0.3 \mathrm{mg} / \mathrm{kg}$ dose of MDPV. In contrast, at all time points postadministration, there were significant differences between saline and the $3.0 \mathrm{mg} / \mathrm{kg}$ dose of MDPV $(p<0.05)$. There was a significant main effect of drug (MDPV) treatment for locomotor activity $\left(\mathrm{F}_{3,24}=11.8 p<0.0001\right.$; two-way ANOVA, drug main factor $\times$ time repeated factor) and stereotypy $\left(\mathrm{F}_{3,24}=8.7 p=0.0004\right.$; two-way ANOVA, drug main factor $\times$ time repeated factor). Importantly, repeated-measures ANOVA results confirmed a significant drug $\times$ time interaction for locomotor activity $\left(\mathrm{F}_{87,696}=9.4\right.$, $p<0.0001)$ and stereotypy $\left(\mathrm{F}_{87,696}=7.9, p<0.0001\right.$; Sidak's multiple-comparison post hoc test, $p<0.05$ ).

The administration of cis-flupenthixol did not affect the locomotor or stereotypic activity during the 30 -min period immediately preceding MDPV injection. However, cisflupenthixol attenuated locomotor activity and stereotopy in rats that had received $3.0 \mathrm{mg} / \mathrm{kg}$ of MDPV. The attenuated response in rats with dopamine receptor blockade was observed from 50-90 min following MDPV administration $(100-150 \mathrm{~min}$ in Figure $7 \mathrm{a}, p<0.05)$. This return to baseline after $110 \mathrm{~min}$ is consistent with the idea that flupenthixol reduces the locomotor stimulant effects of MDPV. The effect of MDPV and flupenthixol+MDPV on locomotor activity and stereotopy showed a similar effect (Figure 7b).

\section{Systemic Physiological Effects of MDPV Administration}

Core body temperatures and respiratory rates were recorded during functional scanning and analyzed to determine the potential effect of drug-associated physiological perturbations on imaging results. Results are shown in Figures 8a and $b$. Respiratory rates were very stable across saline and MDPV dose groups (Figure 8b, 60-65 strokes per minute for $0-3 \mathrm{mg} / \mathrm{kg} \mathrm{MDPV).} \mathrm{Although} \mathrm{there} \mathrm{was} \mathrm{a} \mathrm{tendency} \mathrm{for}$ the highest dose of MDPV to reduce body temperature (Figure $8 \mathrm{a}, 36^{\circ} \mathrm{C}$ for $3 \mathrm{mg} / \mathrm{kg}$ compared with $37^{\circ} \mathrm{C}$ for saline), this did not reach statistical significance $(p=0.058$, nonparametric Mann-Whitney test). Animals treated with cis-flupenthixol before MDPV showed a significantly higher respiratory rate (and no change in body temperature) compared with the saline and MDPV-only groups (Figure $8 b$ ).

In a separate cohort of animals, containing both control and $3 \mathrm{mg} / \mathrm{kg}$ MDPV-treated rats, we assessed heart rates and arterial $\mathrm{O}_{2}$ tension (Figures $8 \mathrm{c}$ and d). All rats $(n=8)$ showed very stable heart rate and percent arterial $\mathrm{O}_{2}$ tension over the course of a 20-min physiological monitoring period (measured 30-40 min after dexmedetomidine injection). Although it appeared that MDPV had more variable effects on both heart rate and $\mathrm{O}_{2}$, these physiological variables were not significantly different when compared with control rats (heart rate $t_{6}=0.78, p=0.46$; arterial $\mathrm{O}_{2} t_{6}=0.47, p=0.65$ ). This holds true when comparing the initial and end of the measurement period (heart rate $t_{6}=1.4, p=0.21$; arterial $\mathrm{O}_{2}$ 

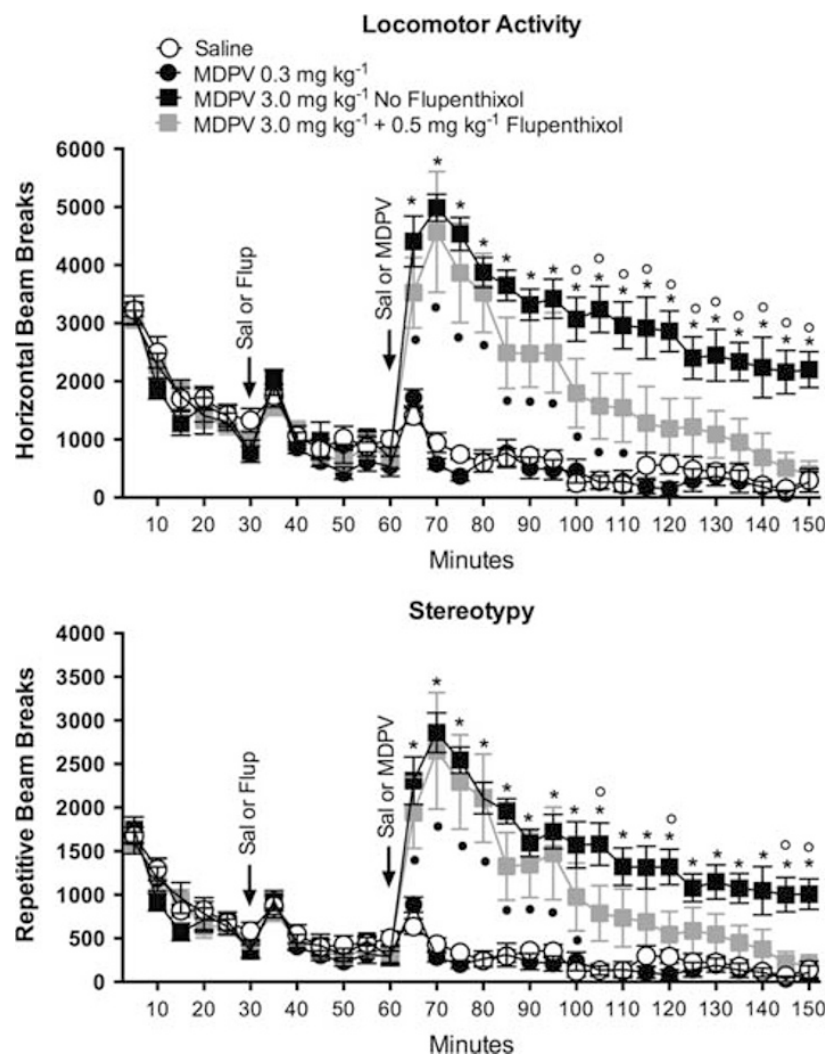

Figure 7 Pretreatment with the dopamine receptor blocker caused a faster decline in 3,4-methylenedioxypyrovalerone (MDPV)-induced locomotor activity. Data are presented as mean $\pm \mathrm{SE}(n=6-8$ rats per treatment). A significant main effect of drug treatment was observed for locomotor activity $\left(F_{3,24}=11.8 p<0.000\right.$ I; two-way analysis of variance (ANOVA) drug main factor $\times$ time repeated factor) and stereotypy $\left(F_{3,24}=8.7, p=0.0004\right.$; two-way ANOVA drug main factor $\times$ time repeated factor). *, MDPV $3.0 \mathrm{mg} / \mathrm{kg}$ significantly different from saline; $\boldsymbol{O}$. Flup+MDPV significantly different from saline; 0 , MDPV $3.0 \mathrm{mg} / \mathrm{kg}$ significantly different from Flup+MDPV (Sidak's multiple comparison post hoc test, $p<0.05$ ). Flup, cis-flupenthixol.

$\left.t_{6}=1.2, p=0.28\right)$. Thus, collectively, these results do not support the notion that the effect of MDPV on functional connectivity is linked to changes in these physiological variables (respiratory activity, body temperature, heart rate, and changes in arterial $\mathrm{O}_{2}$ ).

\section{DISCUSSION}

In the present study, MDPV administration reduced brain functional connectivity at the highest doses examined (1.0 and $3.0 \mathrm{mg} / \mathrm{kg}$, intraperitoneally). The reduction in synchronous BOLD activity occurred across a large number of ROIs that covered most of the forebrain and regions of midbrain (Figures 3, 4 and 5). These regions included areas involved in reinforcement learning, habit learning, and drug seeking, as well as regions involved in higher-order cognitive functions, learning and memory, and sensory and associative processing. The results show a novel functional signature in the MDPV-exposed brain that could underlie some of its negative effects reported in the clinical literature. The observed reduction in brain functional connectivity is consistent with the reported widespread range of impairments across sensorimotor, cognitive, and emotional domains that are observed during MDPV intoxication.

Animal studies (Aarde et al, 2013; Baumann et al, 2012; Bonano et al, 2014; Gatch et al, 2013; Huang et al, 2012; Marusich et al, 2014b; Watterson et al, 2014) and in vitro monoamine transporter assays (Baumann et al, 2012) have shown that MDPV produces typical psychostimulant-like effects, with a mechanism of action that is similar to and, yet, more powerful and longer lasting than cocaine. The biological activity of bath salts, including MDPV, is thought to be largely mediated through their effects on mesostriatal monoaminergic neurotransmission (Cozzi et al, 1999). MDPV binds to human DATs expressed in oocytes and elicits an outward current that is greater in magnitude and of longer duration than that evoked by cocaine (Kolanos et al, 2013; Sonders et al, 1997). In addition to its prolonged effects on blocking DAT-mediated transport, MDPV is also a potent norepinephrine transporter (NET) inhibitor, with greater potency for NET than cocaine or METH (Simmler et al, 2013). Consistent with its potent activity at striatal DATs and NETs, MDPV is also a potent locomotor stimulant (Gatch et al, 2013) and produces conditioned place preference in both rats and mice (Karlsson et al, 2014; King et al, 2015). It also significantly elevates extracellular levels of dopamine in the striatum (Baumann et al, 2012). However, MDPV shows negligible levels of activity as a substrate for the DAT and NET or as a dopamine $\mathrm{D}_{1} / \mathrm{D}_{2}$ receptor ligand (Simmler et al, 2013). The methylenedioxy substitution confers MDMA-like discriminative stimulus properties, empathogenic effects, and reduces its amphetamine-like discrimination properties (Dal Cason et al, 1997). This chemical moiety might also underlie its high blood brain-barrier penetrance and prolonged duration of action compared with other bath salt constituents (Bonano et al, 2014). MDPV also produces higher rates of intravenous self-administration compared with METH (Aarde et al, 2013), and extended access to MDPV causes escalation of drug intake at multiple doses (Watterson et al, 2014).

An interesting aspect of MDPV's mechanism of action in relation to the findings of the present study is its systemic metabolic breakdown. A dose range of $0.5-2.0 \mathrm{mg} / \mathrm{kg}$ (subcutaneous) produces a maximum plasma concentration at about 15-18 min in rats (Anizan et al, 2014), which in the present study could have occurred even sooner given the intraperitoneal route of administration. In contrast, its main metabolites, 3,4-dihydroxy-pyrovalerone and 4-hydroxy-3methoxy-pyrovalerone (Meyer et al, 2010; Strano-Rossi et al, 2010), rise gradually, with peak concentrations occurring much later (between 190 and $260 \mathrm{~min}$; Anizan et al, 2014). It might be expected then that at the time of image acquisition in the present study, plasma levels of both metabolites were rising towards peak concentrations. This suggests the possibility that the reduced functional connectivity observed at $1 \mathrm{~h}$ following intraperitoneal MDPV administration could be, in part, associated with these metabolites. To our knowledge, the metabolites themselves have not been tested for locomotor-activating effects. However, Anizan et al (2014) observed a weak relationship between peak concentrations of hydroxylated metabolites of MDPV and levels of locomotor activity and stereotypy. This contrasts with the potent effects of MDPV itself on locomotor activity, which 

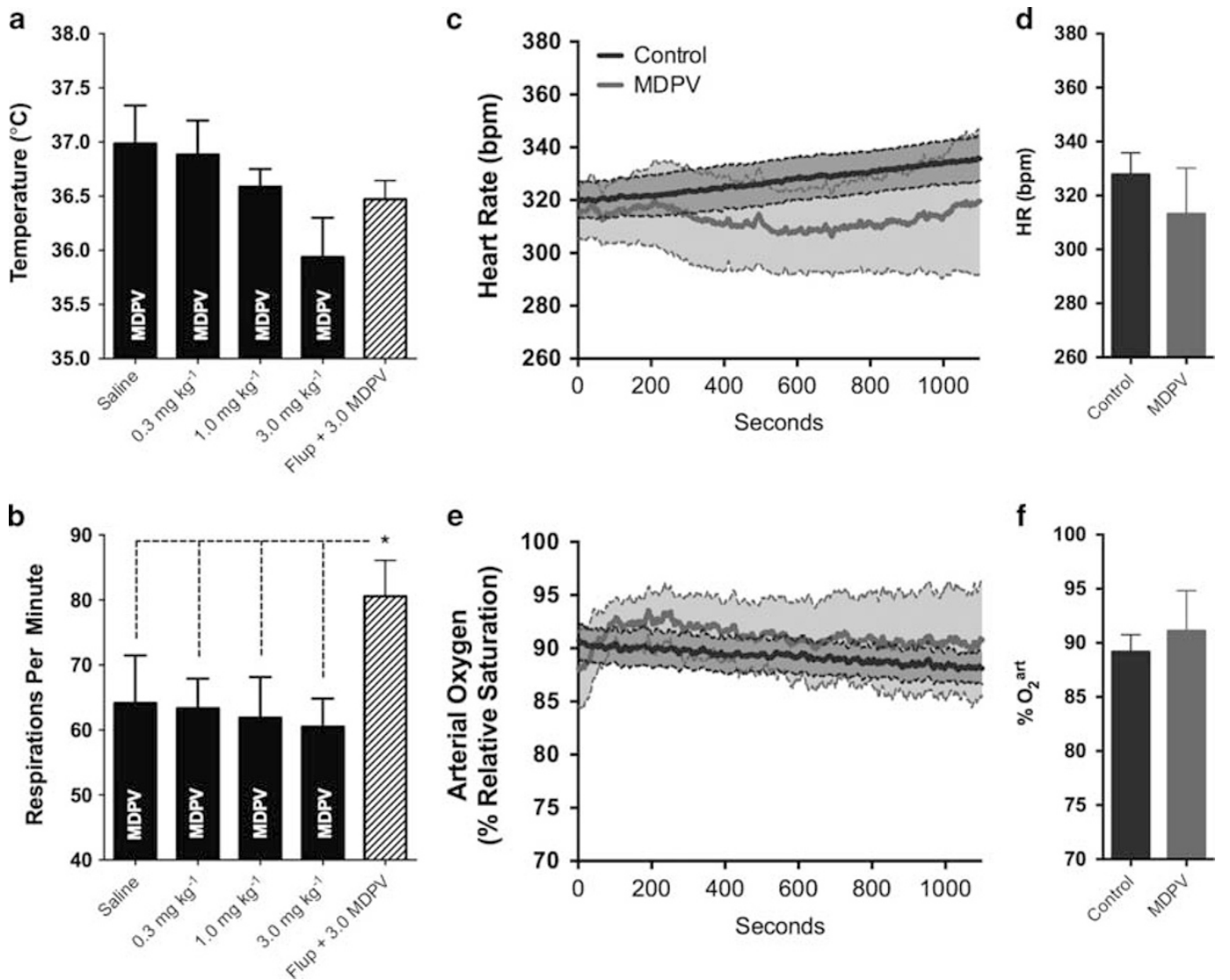

Figure 8 Physiological measures are stable I h after 3,4-methylenedioxypyrovalerone (MDPV) administration. (a) Rectal temperature, (b) respiratory activity, $(c, d)$ heart rate $(H R)$, and $(e, f)$ relative arterial $\mathrm{O}_{2}$ tension. Data are presented as mean $\pm \mathrm{SE}$. No significant differences were observed.

are much greater than that of cocaine $(\sim 10$ times more potent) (Baumann et al, 2012). Therefore, it is not likely that these metabolites have a role in increased MDPV-induced locomotor activity and stereotypy. It is important to note that at this time point ( $1 \mathrm{~h}$ postadministration) striatal MDPV concentrations are still near peak levels, although plasma levels have dropped to below 50\% peak concentrations (Novellas et al, 2015). Thus, activity of MDPV in striatal regions might account, in part, for our observed results.

In addition to its rewarding effects, MDPV is reported to produce aversive effects (Merluzzi et al, 2014). Rats acquire conditioned taste aversion to saccharine solution following a single administration of MDPV doses within the range of those used in the present study. This effect is consistent with the late onset negative symptoms following MDPV intake that have been reported in the clinical literature (Penders and Gestring, 2011; Stoica and Felthous, 2013). It will be important to determine in future studies whether the reductions in functional connectivity observed in the present study are associated with aversive effects of MDPV. Another particularly intriguing aspect of MDPV's effect on functional connectivity was the marked difference in its effect when going from 0.3 to $1 \mathrm{mg} / \mathrm{kg}$. This threefold increase in dose was sufficient to powerfully hinder resting state networks that were active in saline and low-dose MDPV conditions. Although speculative at this moment, these results could signify that the higher dose alters a neural substrate that specifically affects resting state functional connectivity, whereas the lower dose does not.

Blocking dopamine receptors with cis-flupenthixol attenuated the locomotor stimulant effects of MDPV (Figure 7). The activity declined more rapidly in animals pretreated with cis-flupenthixol, although the initial (peak) magnitude of the locomotor response to MDPV was not affected. These results suggest that the central mechanisms of the locomotor stimulant actions of MDPV at least partly involve dopaminergic stimulation, which was attenuated by cis-flupenthixol pretreatment. These results are consistent with a recent study showing that MDPV stimulated locomotor activity at the same doses and administration routes used in the present work (Novellas et al, 2015). Novellas et al (2015) found that pretreatment with haloperidol, an antagonist for dopamine and other amine neurotransmitter receptors, $10 \mathrm{~min}$ before MDPV administration completely blocked the locomotor stimulant actions of MDPV. When compared with the present partial effects of the more selective dopamine receptor blocker, this might suggest that other neurotransmitter systems are involved in MDPV's potent stimulant actions. Importantly, in the present study a significant effect of flupenthixol on MDPV-induced locomotor activity was present 50-60 min after MDPV administration, which corresponds to the time point at which imaging data were collected.

As cis-flupenthixol did not affect the MDPV-induced reduction in functional connectivity, these findings suggest 
that a mechanism involving other aspects of dopamine neurotransmission (other than dopamine receptor stimulation) is responsible for the effects of MDPV on functional connectivity. Interestingly, Wenzel et al (2013) found that dopamine receptor blockade with a similar dose of cisflupenthixol reduced cocaine-induced place preference but did not affect the more delayed place aversion (Wenzel et al, 2013). These findings are consistent with the dissociation between the effects of cis-flupenthixol on MDPV-induced locomotor activity and functional connectivity changes and provide a potential link between reductions in functional connectivity and negative affect induced by MDPV. It should be pointed out, however, that while cis-flupenthixol shows high selectivity for dopamine receptors (Meller et al, 1985), and reduces cocaine seeking in rats (Ahmed and Koob, 2004), it does not distinguish between the dopamine $D_{1}$ and $\mathrm{D}_{2}$ receptor subtypes. Therefore, it is possible that other aspects of dopamine neurotransmission, such as direct actions at the presynaptic transporter, might mediate the effects of MDPV on functional connectivity.

It will be an important goal of future research to more directly investigate the dopaminergic and (putative) non-dopaminergic mechanisms of these effects. A possible mechanism could involve the noradrenergic system (Baumann et al, 2012; Marusich et al, 2014a). MDPV binds to NET and increases norepinephrine availability. The noradrenergic system projects extensively to cortical and subcortical regions, which is consistent with the widespread effects of MDPV on functional connectivity. Noradrenergic inputs to the bed nucleus of stria terminalis and central nucleus of the amygdala, which are involved in the expression of anxiety-like behavior in rats (Fendt et al, 2005). Blockade of $\beta$-adrenergic receptors in these regions attenuates the delayed aversive (but not the immediate rewarding) effects of cocaine (Wenzel et al, 2014). Hence, it is possible that activation of adrenergic receptors may mediate (at least in part) the reported aversive effects of MDPV. Although, to our knowledge, the role of noradrenergic signaling in functional connectivity has not been evaluated in animal models, a recent study using the NET inhibitor atomoxetine in Parkinson's disease patients reported increased functional connectivity between the right inferior frontal gyrus and the dorsal anterior cingulate cortex (Borchert et al, 2016). While it is difficult to compare these results to our present work, the direction of functional connectivity changes with a DAT/NET blocker (decreased with MDPV) compared with a NET inhibitor (increased with atomoxetine) reduces support for NET involvement in MDPV's effect on functional connectivity.

There have been no functional connectivity studies to date that have focused on the effects of MDPV or other bath salt constituents. There have been a number of studies in humans, non-human primates, and rodents, however, that have assessed the effects of other dopaminergic agents on functional connectivity. Methylphenidate administration to cocaine users reduced high levels of functional connectivity between the ventral and dorsal striatum/globus pallidus and increased connectivity between ventral striatum and temporal structures (Konova et al, 2013). Acute administration of the dopamine receptor antagonist haloperidol reduced connectivity between structures comprising the default mode network and the midbrain in healthy volunteers, whereas acute administration of levodopa increased connectivity among these same regions (Cole et al, 2013). In contrast, reductions in resting state functional connectivity are reported in human subjects following acute cocaine administration ( $\mathrm{Li}$ et al, 2000).

Functional connectivity is also altered following chronic stimulant use. After 2 weeks of abstinence, cocainedependent subjects showed significantly reduced functional connectivity between frontal cortical and dorsal striatal regions in comparison with controls (Camchong et al, 2011). Similar reductions in frontostriatal functional networks are reported for non-human primates trained to self-administer cocaine for 6 years (Murnane et al, 2015). Functional connectivity is reduced between VTA and thalamus, NAc, and lentiform nucleus of active cocaine users ( $\mathrm{Gu}$ et al, 2010). Abstinent users showed functional connectivity reductions between the amygdala and prefrontal cortex and between the hippocampus and prefrontal cortex ( $\mathrm{Gu}$ et al, 2010). Finally, cocaine-dependent subjects who relapse within 30 days of treatment display reduced connectivity between amygdala subregions and ventromedial and rostral anterior cingulate cortices (McHugh et al, 2014). It is important to note that altered functional connectivity in cocaine users may depend on the duration of abstinence before relapse (Camchong et al, 2011; McHugh et al, 2013) and is associated with cognitive deficits (Motzkin et al, 2014). Similar, and perhaps even greater, effects might occur following chronic use of MDPV.

Finally, while it is possible that systemic physiological perturbations following MDPV administration can affect the BOLD signal, we did not observe any physiological changes (eg, body temperature, respiration, heart rate, relative arterial oxygen tension) in response to MDPV. It should be noted that these physiological measures were collected in sedated rats and, therefore, most likely differ from the awake behaving rat. It is interesting that no significant changes in body temperature at any dose of MDPV were observed. Psychostimulants typically increase body temperature immediately following administration (King et al, 2014). A recent report also showed that MDPV can increase body temperature (King et al, 2014), but it should be noted that others did not find an effect of MDPV on body temperature (Aarde et al, 2013; Merluzzi et al, 2014) or body temperature changes that are associated with ambient temperature conditions (Kiyatkin et al, 2015). Our fMRI measurements were taken $1 \mathrm{~h}$ following MDPV administration. At this time point, there has been a report of elevated muscle (but not skin) temperature levels, but the putative vasoconstrictive actions have subsided (Wakabayashi et al, 2015).

In conclusion, the results of the present study indicate that acute administration of MDPV dose-dependently reduces functional connectivity. This effect is observed in multiple brain regions included in the present analysis and is measurable at 50-60 min after administration. Blocking dopamine receptors does not prevent the reduced connectivity, suggesting that dopamine receptor overstimulation is not a major cause of the reduced functional connectivity. These findings suggest that an alternative mechanism of action for MDPV may exist. While one candidate mechanism might involve MDPV effects via NET (Simmler et al, 2012), an additional and unexplored possibility, based on some clinical reports, is a mechanism indirectly involving 
$\gamma$-aminobutyric acid (GABA). Anxiolytic agents acting through $\mathrm{GABA}_{\mathrm{A}}$, such as benzodiazepines (diazepam, lorazepam) and valproate, have proven effective in ameliorating the negative symptoms of bath salt intoxication (Bertol et al, 2014; Stoica and Felthous, 2013). Because these agents act via a different mechanism not involving monoaminergic transmission, this may be a target that could receive less attention. As GABAergic neurons modulate cortical synchrony (Fries, 2009) and loss of synchrony can occur in psychosis (Moran and Hong, 2011), GABA-mediated rescue of functional connectivity in the regions reported here (prelimbic cortex, insular cortex, NAc) may be of clinical interest (Bertol et al, 2014; Stoica and Felthous, 2013). Additionally, although not considered here, the reduction in resting state functional connectivity could represent a functional signature associated with neurodegenerative effects that have been reported with other stimulant drugs (Blum et al, 2013; Gold et al, 2009). Finally, future work should consider the combinations of bath salt agents that are typically abused. There is a growing list of synthetic cathinones (eg, mephedrone, methylone) but a shortage of data regarding their in vivo effects on brain function.

\section{FUNDING AND DISCLOSURE}

The authors declare no conflict of interest.

\section{ACKNOWLEDGMENTS}

KT was supported by University Scholars Program of the University of Florida. We thank the Advanced Magnetic Resonance Imaging and Spectroscopy (AMRIS) facility for their continued support (National Science Foundation Cooperative Agreement No. DMR-1157490 and the State of Florida). We thank Dr Craig F Ferris and Dr Praveen Kulkarni (Northeastern University, Boston, MA) for their support with the segmented atlas of the rat brain and to Dr Amanda K. Welch for editorial assistance. This work was funded by National Institute on Drug Abuse Grant R21 DA038009 to MF.

\section{REFERENCES}

Aarde SM, Huang PK, Creehan KM, Dickerson TJ, Taffe MA (2013). The novel recreational drug 3,4-methylenedioxypyrovalerone (MDPV) is a potent psychomotor stimulant: self-administration and locomotor activity in rats. Neuropharmacology 71: 130-140.

Ahmed SH, Koob GF (2004). Changes in response to a dopamine receptor antagonist in rats with escalating cocaine intake. Psychopharmacology 172: 450-454.

Albert R, Barabasi AL (2002). Statistical mechanics of complex networks. Rev Mod Phys 74: 47-97.

Anizan S, Concheiro M, Lehner KR, Bukhari MO, Suzuki M, Rice KC et al (2014). Linear pharmacokinetics of 3,4-methylenedioxypyrovalerone (MDPV) and its metabolites in the rat: relationship to pharmacodynamic effects. Addict Biol 21: 339-347.

Anticevic A, Brumbaugh MS, Winkler AM, Lombardo LE, Barrett J, Corlett PR et al (2013). Global prefrontal and fronto-amygdala dysconnectivity in bipolar I disorder with psychosis history. Biol Psychiatry 73: 565-573.

Baumann MH, Partilla JS, Lehner KR, Thorndike EB, Hoffman AF, Holy $\mathrm{M}$ et al (2012). Powerful cocaine-like actions of 3,4methylenedioxypyrovalerone (MDPV), a principal constituent of psychoactive 'bath salts' products. Neuropsychopharmacology 38: 552-562.

Bertol E, Mari F, Boscolo Berto R, Mannaioni G, Vaiano F, Favretto D (2014). A mixed MDPV and benzodiazepine intoxication in a chronic drug abuser: determination of MDPV metabolites by LC-HRMS and discussion of the case. Forensic Sci Int 243: 149-155.

Blum K, Foster Olive M, Wang KK, Febo M, Borsten J, Giordano J et al (2013). Hypothesizing that designer drugs containing cathinones ('bath salts') have profound neuro-inflammatory effects and dangerous neurotoxic response following human consumption. Med Hypotheses 81: 450-455.

Bonano JS, Glennon RA, De Felice LJ, Banks ML, Negus SS (2014). Abuse-related and abuse-limiting effects of methcathinone and the synthetic 'bath salts' cathinone analogs methylenedioxypyrovalerone (MDPV), methylone and mephedrone on intracranial self-stimulation in rats. Psychopharmacology 231: 199-207.

Borchert RJ, Rittman T, Passamonti L, Ye Z, Sami S, Jones SP et al (2016). Atomoxetine enhances connectivity of prefrontal networks in Parkinson's disease. Neuropsychopharmacology (doi:10.1038/npp.2016.18).

Camchong J, MacDonald AW III, Nelson B, Bell C, Mueller BA, Specker $S$ et al (2011). Frontal hyperconnectivity related to discounting and reversal learning in cocaine subjects. Biol Psychiatry 69: 1117-1123.

Chiacchiaretta P, Ferretti A (2015). Resting state BOLD functional connectivity at 3T: spin echo versus gradient echo EPI. PLoS One 10: 0120398.

Cole DM, Oei NY, Soeter RP, Both S, van Gerven JM, Rombouts SA et al (2013). Dopamine-dependent architecture of corticosubcortical network connectivity. Cerebr Cortex 23: 1509-1516.

Cox RW (1996). AFNI: software for analysis and visualization of functional magnetic resonance neuroimages. Comput Biomed Res 29: $162-173$.

Cozzi NV, Sievert MK, Shulgin AT, Jacob P 3rd, Ruoho AE (1999). Inhibition of plasma membrane monoamine transporters by beta-ketoamphetamines. Eur J Pharmacol 381: 63-69.

Dal Cason TA, Young R, Glennon RA (1997). Cathinone: an investigation of several $N$-alkyl and methylenedioxy-substituted analogs. Pharmacol Biochem Behav 58: 1109-1116.

De Felice LJ, Glennon RA, Negus SS (2014). Synthetic cathinones: chemical phylogeny, physiology, and neuropharmacology. Life Sci 97: 20-26.

Diekhoff S, Uludag K, Sparing R, Tittgemeyer M, Cavusoglu M, von Cramon DY et al (2011). Functional localization in the human brain: gradient-echo, spin-echo, and arterial spin-labeling fMRI compared with neuronavigated TMS. Hum Brain Mapp 32: 341-357.

Duong TQ, Yacoub E, Adriany G, Hu X, Ugurbil K, Kim SG (2003). Microvascular BOLD contribution at 4 and $7 \mathrm{~T}$ in the human brain: gradient-echo and spin-echo fMRI with suppression of blood effects. Magnet Resonan Med 49: 1019-1027.

Duong TQ, Yacoub E, Adriany G, Hu X, Ugurbil K, Vaughan JT et al (2002). High-resolution, spin-echo BOLD, and CBF fMRI at 4 and 7T. Magnet Resonan Med 48: 589-593.

Ewing SG, Grace AA (2013). Long-term high frequency deep brain stimulation of the nucleus accumbens drives time-dependent changes in functional connectivity in the rodent limbic system. Brain Stimul 6: 274-285.

Febo M, Gonzalez-Rodriguez LA, Capo-Ramos DE, Gonzalez-Segarra NY, Segarra AC (2003). Estrogen-dependent alterations in D2/D3-induced $G$ protein activation in cocaine-sensitized female rats. J Neurochem 86: 405-412.

Febo M, Jimenez-Rivera CA, Segarra AC (2002). Estrogen and opioids interact to modulate the locomotor response to cocaine in the female rat. Brain Res 943: 151-161.

Febo M, Segarra AC, Nair G, Schmidt K, Duong TQ, Ferris CF (2004a). The neural consequences of repeated cocaine exposure 
revealed by functional mri in awake rats. Neuropsychopharmacology 30: $936-943$.

Febo M, Segarra AC, Nair G, Schmidt K, Duong TQ, Ferris CF (2005). The neural consequences of repeated cocaine exposure revealed by functional MRI in awake rats. Neuropsychopharmacology 30: 936-943.

Febo M, Segarra AC, Tenney JR, Brevard ME, Duong TQ, Ferris CF (2004b). Imaging cocaine-induced changes in the mesocorticolimbic dopaminergic system of conscious rats. J Neurosci Methods 139: 167-176.

Fendt M, Siegl S, Steiniger-Brach B (2005). Noradrenaline transmission within the ventral bed nucleus of the stria terminalis is critical for fear behavior induced by trimethylthiazoline, a component of fox odor. J Neurosci 25: 5998-6004.

Ferris CF, Yee JR, Kenkel WM, Dumais KM, Moore K, Veenema AH et al (2015). Distinct BOLD activation profiles following central and peripheral oxytocin administration in awake rats. Front Behav Neurosci 9: 245.

Fries P (2009). Neuronal gamma-band synchronization as a fundamental process in cortical computation. Annu Rev Neurosci 32: 209-224.

Gatch MB, Taylor CM, Forster MJ (2013). Locomotor stimulant and discriminative stimulus effects of 'bath salt' cathinones. Behav Pharmacol 24: 437-447.

Goense JB, Logothetis NK (2006). Laminar specificity in monkey V1 using high-resolution SE-fMRI. Magn Reson Imaging 24: 381-392.

Gold MS, Kobeissy FH, Wang KK, Merlo LJ, Bruijnzeel AW, Krasnova IN et al (2009). Methamphetamine- and traumainduced brain injuries: comparative cellular and molecular neurobiological substrates. Biol Psychiatry 66: 118-127.

Grandjean J, Schroeter A, Batata I, Rudin M (2014). Optimization of anesthesia protocol for resting-state fMRI in mice based on differential effects of anesthetics on functional connectivity patterns. NeuroImage 102 Pt 2: 838-847.

Gu H, Salmeron BJ, Ross TJ, Geng X, Zhan W, Stein EA et al (2010). Mesocorticolimbic circuits are impaired in chronic cocaine users as demonstrated by resting-state functional connectivity. NeuroImage 53: 593-601.

Haiken M (2012). 'Bath Salts' a Deadly New Drug With a Deceptively Innocent Name. New York Times: New York, NY.

Harmer J, Sanchez-Panchuelo RM, Bowtell R, Francis ST (2012). Spatial location and strength of BOLD activation in high-spatialresolution $\mathrm{fMRI}$ of the motor cortex: a comparison of spin echo and gradient echo fMRI at 7T. NMR Biomed 25: 717-725.

Huang PK, Aarde SM, Angrish D, Houseknecht KL, Dickerson TJ, Taffe MA (2012). Contrasting effects of $d$-methamphetamine, 3,4-methylenedioxymethamphetamine, 3,4-methylenedioxypyrovalerone, and 4-methylmethcathinone on wheel activity in rats. Drug Alcohol Depend 126: 168-175.

Jenkinson M, Bannister P, Brady M, Smith S (2002). Improved optimization for the robust and accurate linear registration and motion correction of brain images. NeuroImage 17: 825-841.

John ME, Thomas-Rozea C, Hahn D (2014). Bath salts abuse leading to new onset psychosis and potential for violence. Clin Schizophr Relat Psychoses 20: 1-14.

Jonckers E, Delgado YPR, Shah D, Guglielmetti C, Verhoye M, Van der Linden A (2014). Different anesthesia regimes modulate the functional connectivity outcome in mice. Magn Reson Med 72: 1103-1112.

Karlsson L, Andersson M, Kronstrand R, Kugelberg FC (2014). Mephedrone, methylone and 3,4-methylenedioxypyrovalerone (MDPV) induce conditioned place preference in mice. Basic Clin Pharmacol Toxicol 115: 411-416.

Kaufman MJ, Levin JM, Maas LC, Rose SL, Lukas SE, Mendelson JH et al (1998). Cocaine decreases relative cerebral blood volume in humans: a dynamic susceptibility contrast magnetic resonance imaging study. Psychopharmacology 138: 76-81.

King HE, Wetzell B, Rice KC, Riley AL (2014). 3,4-Methylenedioxypyrovalerone (MDPV)-induced conditioned taste avoidance in the F344/N and LEW rat strains. Pharmacol Biochem Behav 126: 163-169.

King HE, Wetzell B, Rice KC, Riley AL (2015). An assessment of MDPV-induced place preference in adult Sprague-Dawley rats. Drug Alcohol Depend 146: 116-119.

Kiyatkin EA, Kim AH, Wakabayashi KT, Baumann $\mathrm{MH}$, Shaham Y (2015). Effects of social interaction and warm ambient temperature on brain hyperthermia induced by the designer drugs methylone and MDPV. Neuropsychopharmacology 40: 436-445.

Kolanos R, Solis E Jr, Sakloth F, De Felice LJ, Glennon RA (2013). 'Deconstruction' of the abused synthetic cathinone methylenedioxypyrovalerone (MDPV) and an examination of effects at the human dopamine transporter. ACS Chem Neurosci 4: 1524-1529.

Kombian SB, Malenka RC (1994). Simultaneous LTP of nonNMDA- and LTD of NMDA-receptor-mediated responses in the nucleus accumbens. Nature 368: 242-246.

Konova AB, Moeller SJ, Tomasi D, Volkow ND, Goldstein RZ (2013). Effects of methylphenidate on resting-state functional connectivity of the mesocorticolimbic dopamine pathways in cocaine addiction. JAMA Psychiatry 70: 857-868.

Li SJ, Biswal B, Li Z, Risinger R, Rainey C, Cho JK et al (2000). Cocaine administration decreases functional connectivity in human primary visual and motor cortex as detected by functional MRI. Magn Reson Med 43: 45-51.

Lu H, Chefer S, Kurup PK, Guillem K, Vaupel DB, Ross TJ et al (2012a). fMRI response in the medial prefrontal cortex predicts cocaine but not sucrose self-administration history. NeuroImage 62: 1857-1866.

Lu H, Zou Q, Chefer S, Ross TJ, Vaupel DB, Guillem K et al (2014). Abstinence from cocaine and sucrose self-administration reveals altered mesocorticolimbic circuit connectivity by resting state MRI. Brain Connect 4: 499-510.

Lu H, Zou Q, Gu H, Raichle ME, Stein EA, Yang Y (2012b). Rat brains also have a default mode network. Proc Natl Acad Sci USA 109: 3979-3984.

Lui S, Deng W, Huang X, Jiang L, Ma X, Chen H et al (2009). Association of cerebral deficits with clinical symptoms in antipsychotic-naive first-episode schizophrenia: an optimized voxel-based morphometry and resting state functional connectivity study. Am J Psychiatry 166: 196-205.

Luo F, Xi ZX, Wu G, Liu C, Gardner EL, Li SJ (2004). Attenuation of brain response to heroin correlates with the reinstatement of heroin-seeking in rats by fMRI. NeuroImage 22: 1328-1335.

Marder J (2012). Bath Salts: The Drug That Never Lets Go PBS Newshour. Available at http://www.pbs.org/newshour/spc/multi media/bath-salts/ (date last accessed 31 March 2016).

Marota JJ, Mandeville JB, Weisskoff RM, Moskowitz MA, Rosen BR, Kosofsky BE (2000). Cocaine activation discriminates dopaminergic projections by temporal response: an fMRI study in Rat. NeuroImage 11: 13-23.

Marusich JA, Antonazzo KR, Wiley JL, Blough BE, Partilla JS, Baumann MH (2014a). Pharmacology of novel synthetic stimulants structurally related to the 'bath salts' constituent 3,4-methylenedioxypyrovalerone (MDPV). Neuropharmacology 87: 206-213.

Marusich JA, Antonazzo KR, Wiley JL, Blough BE, Partilla JS, Baumann MH (2014b). Pharmacology of novel synthetic stimulants structurally related to the 'bath salts' constituent 3,4methylenedioxypyrovalerone (MDPV). Neuropharmacology 87: 206-213.

McCracken CB, Grace AA (2009). Nucleus accumbens deep brain stimulation produces region-specific alterations in local field potential oscillations and evoked responses in vivo. J Neurosci 29: 5354-5363.

McHugh MJ, Demers CH, Braud J, Briggs R, Adinoff B, Stein EA (2013). Striatal-insula circuits in cocaine addiction: implications for impulsivity and relapse risk. Am J Drug Alcohol Abuse 39: $424-432$. 
McHugh MJ, Demers CH, Salmeron BJ, Devous MD Sr., Stein EA, Adinoff B (2014). Cortico-amygdala coupling as a marker of early relapse risk in cocaine-addicted individuals. Front Psychiatry 5: 16.

Meller E, Bohmaker K, Goldstein M, Friedhoff AJ (1985). Inactivation of D1 and D2 dopamine receptors by $\mathrm{N}$-ethoxycarbonyl-2ethoxy-1,2-dihydroquinoline in vivo: selective protection by neuroleptics. J Pharmacol Exp Ther 233: 656-662.

Merluzzi AP, Hurwitz ZE, Briscione MA, Cobuzzi JL, Wetzell B, Rice KC et al (2014). Age-dependent MDPV-induced taste aversions and thermoregulation in adolescent and adult rats. Dev Psychobiol 56: 943-954.

Meyer MR, Wilhelm J, Peters FT, Maurer HH (2010). Beta-keto amphetamines: studies on the metabolism of the designer drug mephedrone and toxicological detection of mephedrone, butylone, and methylone in urine using gas chromatography-mass spectrometry. Anal Bioanal Chem 397: 1225-1233.

Moran LV, Hong LE (2011). High vs low frequency neural oscillations in schizophrenia. Schizophr Bull 37: 659-663.

Motzkin JC, Baskin-Sommers A, Newman JP, Kiehl KA, Koenigs M (2014). Neural correlates of substance abuse: reduced functional connectivity between areas underlying reward and cognitive control. Hum Brain Mapp 35: 4282-4292.

Murnane KS, Gopinath KS, Maltbie E, Daunais JB, Telesford QK, Howell LL (2015). Functional connectivity in frontal-striatal brain networks and cocaine self-administration in female rhesus monkeys. Psychopharmacology 232: 745-754.

Murray BL, Murphy CM, Beuhler MC (2012). Death following recreational use of designer drug 'bath salts' containing 3,4methylenedioxypyrovalerone (MDPV). J Med Toxicol 8: 69-75.

Novellas J, Lopez-Arnau R, Carbo ML, Pubill D, Camarasa J, Escubedo E (2015). Concentrations of MDPV in rat striatum correlate with the psychostimulant effect. J Psychopharmacol 29: 1209-1218.

Pawela CP, Biswal BB, Cho YR, Kao DS, Li R, Jones SR et al (2008). Resting-state functional connectivity of the rat brain. Magn Reson Med 59: 1021-1029.

Penders TM, Gestring R (2011). Hallucinatory delirium following use of MDPV: 'Bath Salts'. Gen Hosp Psychiatry 33: 525-526.

Poser BA, Norris DG (2007). Fast spin echo sequences for BOLD functional MRI. MAGMA 20: 11-17.

Prosser JM, Nelson LS (2012). The toxicology of bath salts: a review of synthetic cathinones. J Med Toxicol 8: 33-42.

Sanchez Panchuelo RM, Schluppeck D, Harmer J, Bowtell R, Francis $S$ (2015). Assessing the spatial precision of SE and GEBOLD contrast at 7 Tesla. Brain Topogr 28: 62-65.

Seely KA, Patton AL, Moran CL, Womack ML, Prather PL, Fantegrossi WE et al (2013). Forensic investigation of K2, Spice, and 'bath salt' commercial preparations: a three-year study of new designer drug products containing synthetic cannabinoid, stimulant, and hallucinogenic compounds. Forensic Sci Int 233: 416-422.

Shen H, Kalivas PW (2013). Reduced LTP and LTD in prefrontal cortex synapses in the nucleus accumbens after heroin selfadministration. Int J Neuropsychopharmacol 16: 1165-1167.

Shulgin AT (2009). The Vaults of EROWID: MDPV. EROWID. Available at: https://www.erowid.org/chemicals/mdpv/ (date last accessed 31 March 2016).

Simmler LD, Buser TA, Donzelli M, Schramm Y, Dieu LH, Huwyler J et al (2012). Pharmacological characterization of designer cathinones in vitro. Br J Pharmacol 168: 458-470.

Simmler LD, Buser TA, Donzelli M, Schramm Y, Dieu LH, Huwyler J et al (2013). Pharmacological characterization of designer cathinones in vitro. Br J Pharmacol 168: 458-470.

Sommer IE, Clos M, Meijering AL, Diederen KM, Eickhoff SB (2012). Resting state functional connectivity in patients with chronic hallucinations. PLoS One 7: e43516.
Sonders MS, Zhu SJ, Zahniser NR, Kavanaugh MP, Amara SG (1997). Multiple ionic conductances of the human dopamine transporter: the actions of dopamine and psychostimulants. J Neurosci 17: 960-974.

Stevenson R, Tuddenham L (2014). Novel psychoactive substance intoxication resulting in attempted murder. J Forensic Legal Med 25: 60-61.

Stoica MV, Felthous AR (2013). Acute psychosis induced by bath salts: a case report with clinical and forensic implications. J Forensic Sci 58: 530-533.

Storey JD (2002). A direct approach to false discovery rates. J R Stat Soc Ser B 64: 479-498.

Strano-Rossi S, Cadwallader AB, de la Torre X, Botre F (2010). Toxicological determination and in vitro metabolism of the designer drug methylenedioxypyrovalerone (MDPV) by gas chromatography/mass spectrometry and liquid chromatography/ quadrupole time-of-flight mass spectrometry. Rapid Commun Mass Spectrom 24: 2706-2714.

Substance Abuse and Mental Health Services Administration (SAMHSA) (2014). Substance Use and Mental Health Estimates from the 2013 National Survey on Drug Use and Health: Overview of Findings. The National Survey on Drug Use and Health Report, Rockville, MD, pp 1-8.

Thornton SL, Gerona RR, Tomaszewski CA (2012). Psychosis from a bath salt product containing flephedrone and MDPV with serum, urine, and product quantification. J Med Toxicol 8: 310-313.

Veeneman MM, van Ast $\mathrm{M}$, Broekhoven $\mathrm{MH}$, Limpens $\mathrm{JH}$, Vanderschuren LJ (2012). Seeking-taking chain schedules of cocaine and sucrose self-administration: effects of reward size, reward omission, and alpha-flupenthixol. Psychopharmacology 220: $771-785$.

Wakabayashi KT, Ren SE, Kiyatkin EA (2015). Methylenedioxypyrovalerone (MDPV) mimics cocaine in its physiological and behavioral effects but induces distinct changes in NAc glucose. Front Neurosci 9: 324

Watterson LR, Kufahl PR, Nemirovsky NE, Sewalia K, Grabenauer M, Thomas BF et al (2012). Potent rewarding and reinforcing effects of the synthetic cathinone 3,4-methylenedioxypyrovalerone (MDPV). Addict Biol 19: 165-174.

Watterson LR, Kufahl PR, Nemirovsky NE, Sewalia K, Grabenauer M, Thomas BF et al (2014). Potent rewarding and reinforcing effects of the synthetic cathinone 3,4-methylenedioxypyrovalerone (MDPV). Addict Biol 19: 165-174.

Wenzel JM, Cotten SW, Dominguez HM, Lane JE, Shelton K, Su ZI et al (2014). Noradrenergic beta-receptor antagonism within the central nucleus of the amygdala or bed nucleus of the stria terminalis attenuates the negative/anxiogenic effects of cocaine. J Neurosci 34: 3467-3474.

Wenzel JM, Su ZI, Shelton K, Dominguez HM, von Furstenberg VA, Ettenberg A (2013). The dopamine antagonist cis-flupenthixol blocks the expression of the conditioned positive but not the negative effects of cocaine in rats. Pharmacol Biochem Behav 114-115: 90-96.

Wolf ND, Sambataro F, Vasic N, Frasch K, Schmid M, SchonfeldtLecuona C et al (2011). Dysconnectivity of multiple resting-state networks in patients with schizophrenia who have persistent auditory verbal hallucinations. J Psychiatry Neurosci 36: 366-374.

Yacoub E, Duong TQ, Van De Moortele PF, Lindquist M, Adriany G, Kim SG et al (2003). Spin-echo fMRI in humans using high spatial resolutions and high magnetic fields. Magnet Reson Med 49: 655-664.

Zuo Y, Lu H, Vaupel DB, Zhang Y, Chefer SI, Rea WR et al (2011). Acute nicotine-induced tachyphylaxis is differentially manifest in the limbic system. Neuropsychopharmacology 36: 2498-2512.

Supplementary Information accompanies the paper on the Neuropsychopharmacology website (http://www.nature.com/npp) 